\title{
Comparison of toxicities between Vibrio fluvialis and Vibrio furnissii strains isolated from environmental samples
}

\author{
Tahsina Jainab ${ }^{1}$, Sayeema Hasan ${ }^{1}$, Mohammed Abul Manchur ${ }^{2}$, Mahmuda Yasmin ${ }^{1}$, Jamalun Nessa ${ }^{1}$ and \\ Chowdhury Rafiqul Ahsan ${ }^{1 *}$ \\ ${ }^{I}$ Department of Microbiology, University of Dhaka, Dhaka-1000, Bangladesh; ${ }^{2}$ Department of Microbiology, University of Chittagong, Chittagong-4331, Bangladesh .
}

\begin{abstract}
Gastrointestinal episodes associated with Vibrio species have been rising worldwide in the last few years. In this study, toxicities of two very well characterized $V$. fluvialis and $V$. furnissii strains, isolated from environmental samples, were used to investigate the comparative pathogenicity of these strains. The results showed that there is a positive relationship between toxin production as well as a high interspecies correlation. In the analysis of toxicity, both species showed positive results with close similarity in cell death on BHK-21 cell line and destruction of RBC, which were indicative of cytotoxic and hemolytic activity, respectively. Besides, molecular analysis showed the absence of $c t x, t d h, t r h, s t x 1$ and $s t x 2$ genes. On the other hand, reduced fluid accumulation ratio in rabbit ileal loop assay and paralysis of hind legs of Swiss Albino mice were observed for $V$. furnissi strain, which indicates the differences in pathogenicity between the two species.
\end{abstract}

Keywords: V. fluvialis, V. furnissii, enterotoxicity, cytotoxicity, neurotoxicity, hemolytic activity.

\section{Introduction}

Gastrointestinal pathogens invade or disrupt the intestinal barrier by the action of secreted toxins. They can modify cell physiology by multiple mechanisms, being directly responsible for the pathology of the disease or favoring other processes such as penetration of host barriers, escape from the intracellular environment and manipulation of the immune response, among others ${ }^{1}$. The Vibrionaceae family includes several species of major importance in the clinical field that can cause gastroenteritis. Therefore, Group F vibrios should perhaps form a new genus within the family Vibrionaceae ${ }^{2}$. This group of vibrios has been isolated from cases of diarrhea in Bahrain, Jordan, Bangladesh, and marine and estuarine environments around Britain ${ }^{3,4}$. In this group, the halophilic V. fluvialis phenotypically resembles Aeromonas species ${ }^{5}$ and taxonomically lies between Aeromonas and Vibrio species ${ }^{6}$. Among the halophilic vibrios, it has a close similarity to $V$. furnissii, but, unlike $V$. fluvialis, $V$. furnissii is aerogenic in nature ${ }^{7}$. Strains isolated from diarrheal patients were found to be anaerogenic, whereas those from the environment included both aerogenic and anaerogenic strains ${ }^{4}$. Both the $V$. fluvialis ${ }^{8}$ and $V$. furnissii ${ }^{9}$ have been associated with outbreaks and sporadic cases of acute diarrhea and are resistant to many antimicrobial agents ${ }^{8}$. The largest outbreak of $V$. fluvialis infection was reported in Bangladesh between October 1976 and November 1977, with more than 500 patients $^{10}$.

Several toxins that may be important in pathogenesis have been reported in V. fluvialis including a Chinese hamster ovary (CHO) cell elongation factor, $\mathrm{CHO}$ cell killing factor, enterotoxin-like substance, lipase, protease cytotoxin and hemolysin ${ }^{11,12}$. None of these factors, however, has been correlated with the diarrheal activity, and similarity and dissimilarity between the related substances and the factors are also unclear. The epidemiological importance of $V$. fluvialis was reported in several recent publications ${ }^{13,14}$. V. furnissii is one of the 11 non-cholera Vibrio species pathogenic in humans ${ }^{15}$, which can lead to human gastroenteritis and extra-intestinal infection and is also ubiquitously present in the marine environment. The pathology of $V$. furnissii in gastroenteritis is potentially related to cytolysin and hemolysin production ${ }^{16}$. However, the question regarding the microbiological characteristics, mechanism of pathogenicity, and ecology of these organisms remain mostly unanswered. More studies are necessary to define risk factors and to determine the pathogenesis of these organisms. Therefore, this study addresses comparisons of toxicities between the environmental $V$. fluvialis and $V$. furnissii strains for a better understanding of the pathogenicity of these organisms.

\section{Methods}

Bacterial strains

Samples were collected from Buriganga and Turag rivers surrounding the Dhaka city, shrimp field near Nalta area of Satkhira and ponds near Tala area of Khulna in Bangladesh. After processing, the collected samples were enriched in alkaline peptone water. The characteristic yellow colonies on the Thiosulfate-citrate-bile salt-sucrose (TCBS) agar plate were subcultured on Vibrio Chromogenic agar for white colonies, which was indicative of desired organisms. Salt tolerance was 
determined by growing the strains in Luria broth overnight with shaking at $37{ }^{\%} \mathrm{C}$ with $0 \%, 3 \%, 5 \%, 7 \% 8 \%$ and $10 \%$. And API 20E identification strip was used to characterize the biochemical features.

\section{Molecular Identification and characterization by Polymerase chain reaction ( $P C R)$}

PCR was used to confirm for species-specific identification to target the toxR gene of $V$. fluvialis and $V$. furnissii strains. PCR technique was also done to screen the virulence genes like $\operatorname{ctx} A$, $t d h$, trh, stx 1 and stx2, which encode the enterotoxic activity. Template DNA was prepared by boiling DNA method using fresh culture for PCR assay.

\section{Preparation of culture filtrate}

Fresh cultures of $V$. fluvialis and $V$. furnissii were inoculated into a synthetic medium containing different kinds of amino acids at an incubation temperature of $37{ }^{\%} \mathrm{C}$ for 48 hours with shaking at $120 \mathrm{rpm}$, followed by centrifugation at $8,000 \mathrm{rpm}$ for 10 minutes. The supernatant containing extracellular proteins was used as culture filtrates.

Rabbit Ileal Loop (RIL) assay for determination of enterotoxicity Enterotoxicity of live cells and culture filtrates of the $V$. fluvialis and $V$. furnissii strains were determined following previous methods ${ }^{17,18}$. Albino rabbits (New Zealand strain) weighing 2-3 $\mathrm{kg}$ were used in this study. The animals were fasted for overnight with allowing water prior to testing. A total of 6-8 loops were made per rabbit maintaining proper anesthesia. One $\mathrm{ml}$ of live cells and culture filtrates were injected into each loop. $V$. cholerae 569B was used as positive control and cell free culture media was used as a negative control. Each test was done in three rabbits and separate rabbits were used for live cells and culture filtrates.

\section{Mouse lethality assay}

An indirect method for neurotoxin detection was carried out by mouse lethality assay. Four to six weeks old Swiss albino mice were intraperitonealy injected with $0.1 \mathrm{ml}$ of culture filtrates of the $V$. fluvialis and $V$. furnissii strains and observed for 2-5 days for any physical change viz: paralysis of muscles. E. coli $\mathrm{O} 157: \mathrm{H} 7$ culture filtrate was used as positive control and culture media to prepare the culture filtrate was used the negative control.

\section{Hemolysin assay}

Hemolytic activity of the $V$. fluvialis and $V$. furnissii culture filtrates were investigated by tube hemolysis method, where, sheep blood was centrifuged at 2,000 rpm for $5 \mathrm{~min}$ and the erythrocyte was diluted to about $1.0 \%$ with phosphate buffer saline (PBS). A reaction mixture was prepared with $1 \mathrm{ml}$ of culture filtrate and $0.5 \mathrm{ml}$ of erythrocyte and was incubated at $37{ }^{\mathfrak{\%}} \mathrm{C}$ for 1 hour followed by centrifugation at 2,000 rpm for 5 minutes. The optical density (OD) of the supernatant was measured for released hemoglobin with a spectrophotometer at $450 \mathrm{~nm}$.

Cytotoxicity assay

BHK-21 cell line was used to determine the cytotoxicity of the $V$. fluvialis and V. furnissii culture filtrates. A monolayer of BHK21 was grown in a tissue culture flask using Dulbecco Modified Eagle's medium with 10\% Fetal Bovine Serum and antibiotics (Penicillin, Gentamycin and Streptomycin). After getting confluent growth, $3.5 \times 10^{4}$ cells $/ 450 \mu \mathrm{L}$ were distributed into each well of 24 well cell culture plates and incubated with the proper cultural condition. Then culture filtrates were added to the wells in duplicate and mixed properly. The plate was then incubated for $18-20$ hours at $37{ }^{æ} \% \mathrm{C}$ in a humid atmosphere with $5 \% \mathrm{CO}_{2}$. The cells were then examined under an inverted microscope for necrosis, elongation, or rounding. E. coli $\mathrm{O} 157: \mathrm{H} 7$ culture filtrate was used as positive control and only culture medium was used as the negative control.

\section{Results}

Primary isolation of $V$. fluvialis and $V$. furnissii strains from environmental samples

For the isolation of $V$.fluvialis and $V$. furnissii organisms, samples were enriched in alkaline peptone water (APW) and plated on TCBS medium. All the strains of $V$. fluvialis and $V$. furnissii showed growth in $7 \%$ and $10 \% \mathrm{NaCl}$ but no growth in $0 \% \mathrm{NaCl}$ containing media. The isolates were confirmed by using the API 20E kit (Table 1). Among these isolates, V. fluvialis strain S-10 was isolated from sediment beside the shrimp fields of Satkhira and the $V$. furnissii strain S-18 was isolated from the sediment of a pond in Khulna.

\section{Molecular identification and characterization of toxic genes}

Both the isolates also gave positive results for tox $R$ gene, using its specific primers (Table 1). PCR analysis followed by agarose gel electrophoresis failed to provide the appearance of any desired band for ctxA, tdh, trh, stx 1 and stx 2 from both the $V$. fluvialis and $V$. furnissii strains except in positive control.

\section{Rabbit ileal loop assay}

Both the live cells of $V$. fluvialis and $V$. furnissii strains caused fluid accumulation in the rabbit ileal loop (Figure 1). However, the fluid accumulation ratios varied between these two strains and from rabbit loop to rabbit loop. The fluid accumulation activity of $V$. fluvialis was comparable to the positive control $V$. cholerae 569B strain. Culture filtrates were prepared from both the strains of $V$. fluvialis and $V$. furnissii gave positive ileal loop reactions (Figure 2).

Table 1. Identification of $V$. fluvialis and $V$. furnissii strains

\begin{tabular}{|c|c|c|c|c|c|c|c|c|c|c|c|c|c|c|c|}
\hline Isolate no. & TCBS & $\mathrm{CV}$ & TSI & Gas & Citrate & MR & Oxidase & & & owth & $\mathrm{NaC}$ & Conc & & VF- & API \\
\hline & & & & & & VP & & $0 \%$ & $3 \%$ & $5 \%$ & $7 \%$ & $8 \%$ & $10 \%$ & toxR & $20 \mathrm{E}$ \\
\hline Ref. strain & $\mathrm{Y}$ & W & $+/+$ & - & + & + & + & - & + & + & + & + & + & + & V. fluvialis \\
\hline S-18 & Y & W & $+/+$ & + & + & + & + & - & + & + & + & + & + & + & V. furnissii \\
\hline
\end{tabular}




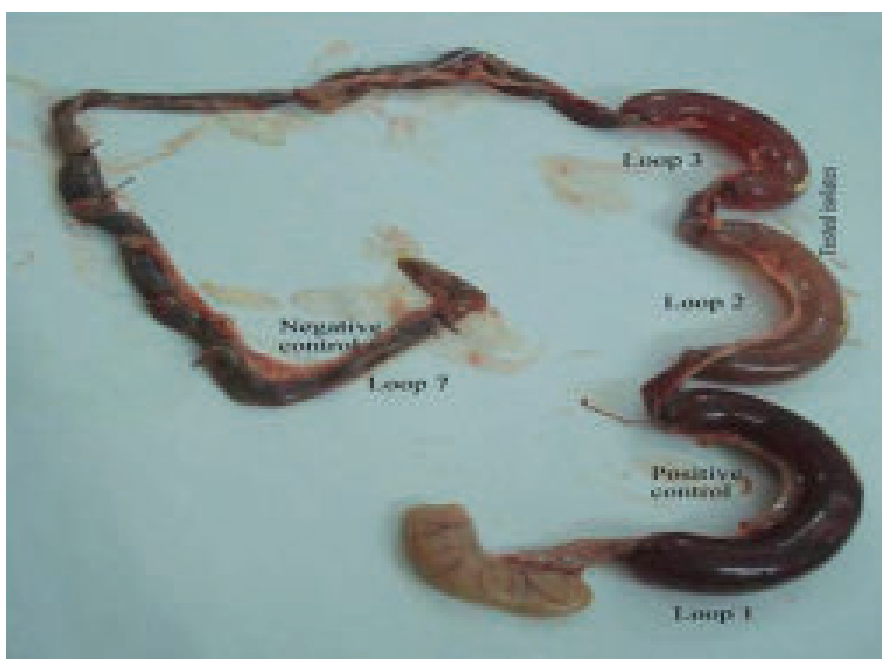

Fig. 1. Fluid accumulation in rabbit ileal loop (Loop 1 and Loop 7 contains live cells of positive control and negative control respectively. Loop 2 and 3 contains live cells of $V$. fluvialis and V. furnissii).

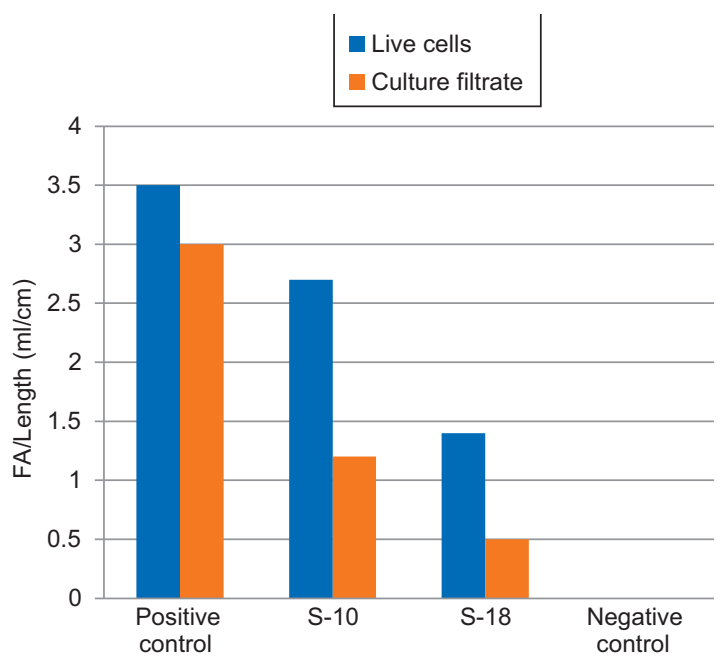

Fig. 2. Graphical representation of mean ratio of fluid accumulation (FA) per length by live cells and culture filtrates of $V$. fluvialis and $V$. furnissii.

Table 2: Comparative results of mouse lethality assay, hemolysis assay and cytotoxicity assay

\begin{tabular}{|c|c|c|c|c|c|c|}
\hline \multirow[t]{2}{*}{ Toxicity assay } & & & \multicolumn{2}{|c|}{ Control } & \multirow{2}{*}{$\begin{array}{l}\text { V. fluvialis } \\
\text { S-10 }\end{array}$} & \multirow{2}{*}{$\begin{array}{l}\text { V. furnissii } \\
\text { S-18 } \\
\end{array}$} \\
\hline & & & Positive & Negative & & \\
\hline $\begin{array}{l}\text { Mouse lethality assa) } \\
\text { (Positive/ Tested) }\end{array}$ & & & $4 / 4$ & $0 / 4$ & $4 / 4$ & $2 / 4$ \\
\hline Hemolysis assay & $\begin{array}{c}\text { Tube method } \\
(\mathrm{OD} @ 450 \mathrm{~nm}) \\
\text { Blood agar plate }\end{array}$ & $\begin{array}{c}\text { Live cells } \\
\text { Culture filtrate }\end{array}$ & $\begin{array}{c}1.113 \\
0.297 \\
\text { Beta hemolysis }\end{array}$ & $\begin{array}{c}0.00 \\
0.00 \\
\text { No hemolysis }\end{array}$ & $\begin{array}{c}\quad 0.774 \\
0.246 \\
\text { Beta hemolysis }\end{array}$ & $\begin{array}{c}\quad 0.841 \\
0.232 \\
\text { Beta hemolysis }\end{array}$ \\
\hline
\end{tabular}

\section{Mouse lethality assay}

Hind limb paralysis and some sort of dizziness were observed within 2-4 days upon intraperitoneal injection of $0.1 \mathrm{ml}$ of culture filtrate. All those mice died within five days after injection (Table 2).

\section{Hemolysis assay}

Both the $V$.fluvialis and $V$. furnissii strains showed positive results, that is the lysis of RBC indicating the production of hemolysin. In the tube method, the development of reddish color throughout the suspension indicated the production of hemolysin by the organisms. The results of hemolytic activity were measured at $450 \mathrm{~nm}$. Live cells of both the isolates also showed a zone of beta hemolysis around their growth (Table 2). E. coli O157:H7 was used as positive control and culture media as a negative control for the detection of hemolytic activity in this study.

\section{Cytotoxicity assay}

BHK-21 cell line was used to determine cytotoxic effect of $V$. fluvialis and $V$. furnissii Culture filtrates of both the isolates showed $25-30 \%$ cell death on BHK-21 cell line (Table 2) when compared with the positive controls.

\section{Discussion}

The members of the Vibrionaceae family namely $V$. mimicus, $V$. fluvialis and $V$. furnissii were also frequently found to be associated with diarrheal outbreaks ${ }^{15,19,20}$. The clinical symptoms of $V$. fluvialis include mild to moderate dehydration, vomiting, fever, abdominal pain and diarrhea ${ }^{5}$. According to Vibrio Reference Laboratory at the CDC, $16 \mathrm{~V}$. furnissii were isolated among 1230 Vibrio and all the V.furnissii isolates were associated with intestinal infections ${ }^{21}$. There are very little information available on the virulence factors associated with infection and much less information on the mechanism of pathogenicity of this organism. Besides, very limited information has been published on the toxicity of $V$. furnissii. So, this study is taken to compare between the toxicities of $V$. fluvialis and $V$. furnissii. In this study, environmental samples were collected from rivers around Dhaka city and southern parts of Bangladesh in the month of November, when water temperature lies between $20-25^{\circ} \mathrm{C}$. Among all 
isolates, V.fluvialis organisms were isolated from Dhaka, Satkhira and Khulna, and V. furnissii organisms solely from Dhaka.

To determine the toxic activities of these organisms, we prepared both live cell preparations and culture filtrates of the $V$. fluvialis and $V$. furnissii strains and carried out in vivo and in vitro experiments. Both the isolates produced different ranges of fluid accumulation in rabbit ileal loop assay and $V$. fluvialis fluid accumulation ratio is almost comparable to the positive control, V. cholerae 569B. Fluid accumulation in the rabbit loop indicated that both $V$. fluvialis and $V$. furnissii strains liberated an enterotoxic-like substance(s) during multiplication in the intestine as well as in the synthetic medium. The differences in fluid accumulation between strains may have been due to the variation in the release of toxins. Cell free culture filtrates of all V. fluvialis strains gave positive ileal loop reactions indicated that enterotoxic substance(s) were liberated during in vitro multiplication in the medium. Similar observations were made with enterotoxic $A$. hydrophila, V. cholerae serotypes other than $\mathrm{O} 1^{19}$. Strain to strain variations in the amount of fluid accumulation was probably due to differences in the quantitative release of the toxin from cells into the medium ${ }^{22}$ and to biological variations in rabbits ${ }^{23}$.

In this study, the fluid accumulating activity by culture filtrates was found to be less than the live cells for both $V$. fluvialis and $V$. furnissii strains. It may occur due to enterotoxin production which is medium dependent and also depends on other factors. Previous report also showed that the enterotoxin production from $V$. fluvialis strains was culture medium dependent and found that clinical strains grown in BHI broth supplemented with $0.5 \% \mathrm{NaCl}$ induced large amounts of fluid accumulation in mouse intestines ${ }^{24}$. BHI media may contain any protein that is toxin destroying or may inhibit the toxin secretion.

The clinical symptoms of gastroenteritis caused by $V$. fluvialis are quite similar to those caused by $V$. cholerae, except for the frequent occurrence of blood in stools ${ }^{25}$. For that reason PCR analysis of $\operatorname{ctx} A$ gene was done to determine the possible reason for fluid accumulation in the rabbit ileal loop. However, no band for the $\operatorname{ctxA}$ gene was obtained in the PCR analysis, when compared with the positive control V. cholerae 569B. So the fluid accumulation factors may be distinct from CT-like enterotoxin. A similar result of $\operatorname{ctx} A$ negative in PCR analysis was also obtained for the $V$. furnissii strain. Subsequently we moved further to determine whether other known toxic genes accountable for enterotoxicities were responsible for fluid accumulation and PCR analysis was done for $t d h$, trh, stx 1 and stx 2 gene responsible for CT, TDH, TRH and STX. However, both $V$. fluvialis and $V$. furnissii strains gave negative results for all genes. More investigation is required to find out the possible reason behind the fluid accumulation of both of the species.

Besides enterotoxicity, the toxin of V. fluvialis and V. furnisssii showed hind limb paralysis in Swiss Albino mice within 2-3 days and all the mice died within five days. These results suggested that both the species produced neurotoxin like substances and in the case of $V$. furnissii it is less severe than $V$. fluvialis. We also found both live cells and culture filtrate of two species were capable of causing the comparable amount of lysis of sheep red blood cells. Production of hemolysin may correlate with the blood in the stool of $V$. fluvialis diarrhea. These results are coherent with the study which reported that $V$. fluvialis hemolysin lyses a wide variety of erythrocytes and is immunologically related to the El Tor hemolysin ${ }^{11}$. Cytotoxicity assay was done on BHK21 cell lines showed positive results as compared to the positive control E.coli O157:H7. In this study, both the isolates showed the comparable amount of cell death (about 25-30\%). All these data clearly showed differences in toxicities between the environmental $V$. fluvialis and $V$. furnissii strains for a better understanding of the pathogenicity of these organisms. More studies are needed on the purification of the toxins to confirm the findings that can evaluate the role of the toxin(s) in the pathogenesis of the enteric disease and to determine their mechanisms of actions on host target cells.

\section{Reference}

1. Ugalde-Silva P, Gonzalez-Lugo O and Navarro-Garcia F. Tight junction disruption induced by type 3 secretion system effectors injected by enteropathogenic and enterohemorrhagic Escherichia coli. Front. Cell. Infect. Microbiol. 2016;6:87.

2. Agarwal RK, Parija SC and Sanyal SC. Taxonomic studies on Vibrio and related genera. Indian J. Med. Res., 1980;71:340-353.

3. Furniss AL, Lee JV, Donovan TJ. Group F, a new Vibrio? Lancet. 1977;10: 565-566

4. Lee JV, Shread P and Furniss AL. The taxonomy of group F organisms: relationships to Vibrio and Aeromonas. J. Appl. Microbiol. 1978;45: ix.

5. Seidler RJ, Allen DA, Colwell RR, Joseph SW and Daily OP. Biochemical characteristics and virulence of environmental group $\mathrm{F}$ bacteria isolated in the United States. Appl Environ Microbiol. 1980;40:715-720.

6. Thekdi RJ, Lakhani AG, Rale VB and Panse MV. An outbreak of food poisoning suspected to be caused by Vibrio fluvialis. J Diarrhoeal Dis Res. 1990;8:163-165.

7. Brenner D Hickman-Brenner FW, Lee JV, Steigerwalt AG, Fanning GR, Hollis DG, Farmer JJ, Weaver RE, Joseph SW and Seidler RJ. Vibrio furnissii (formerly aerogenic biogroup of Vibrio fluvialis), a new species isolated from human feces and the environment. J Clin Microbiol. 1983;18:816-824.

8. Chowdhury G, Pazhani GP, Nair GB, Ghosh A and Ramamurthy T. Transferable plasmid-mediated quinolone resistance in association with extended-spectrum â-lactamases and fluoroquinolone-acetylating aminoglycoside-6'-N-acetyltransferase in clinical isolates of Vibrio fluvialis. Int J Antimicrob Agents. 2011;38:169-173.

9. Dalsgaard A, Glerup P, Høybye LL, Paarup AM, Meza R, et al. Vibrio furnissii isolated from humans in Peru: a possible human pathogen?. Epidemiol Infect. 1997;119:143-149.

10. Huq MI, Alam AK, Brenner DJ and Morris GK. Isolation of Vibrio-like group, EF-6, from patients with diarrhea. J Clin Microbiol. 1980;11:621-624.

11. Rahim $Z$ and Aziz KM. Factors affecting production of haemolysin by strains of Vibrio fluvialis. J Diarrhoeal Dis Res. 1996;14:113-116.

12. Kothary MH, Lowman H, McCardell BA and Tall BD. Purification and characterization of enterotoxigenic El Tor-like hemolysin produced by Vibrio fluvialis. Infect Immun. 2003;71:3213-3220.

13. Chowdhury G, Pazhani GP, Dutta D, Guin S, Dutta S and Ghosh S. Vibrio fluvialis in patients with diarrhea, Kolkata, India. Emerg. Infect. Dis. 2012;18:1868-1871. 
14. Liang P, Cui X, Du X, Kan B and Liang W. The virulence phenotypes and molecular epidemiological characteristics of Vibrio fluvialis in China. Gut Pathog. 2013;5:6.

15. Janda JM, Powers C, Bryant RG and Abbott SL. Current perspectives on the epidemiology and pathogenesis of clinically significant Vibrio spp. Clin Microbiol Rev. 1988;1:245-267.

16. Magalhães V, Castello Filho A, Magalhães M and Gomes TT. Laboratory evaluation on pathogenic potentialities of Vibrio furnissii. Mem Inst Oswaldo Cruz. 1993;88:593-597.

17. De SN and Chatterje DN. An experimental study of the mechanism of action of Vibriod cholerae on the intestinal mucous membrane. J Pathol Bacteriol. 1953;66:559-562.

18. Singh SJ and Sanyal SC. Enterotoxicity of the so-called NAG vibrios. Ann Soc Belge Med Trop. 1978;58:133-140.

19. Chitov T, Kirikaew P, Yungyune P, Ruengprapan N and Sontikun K. An incidence of large foodborne outbreak associated with Vibrio mimicus. Eur. J Clin Microbiol Infect Dis. 2009;28:421-424.
20. Lam SY and Goi LT. Isolations of "group F vibrios" from human stools. Singapore Med J. 1985;26: 300-302.

21. Farmer JJ, III FW, Hickman-Brenner and Kelly MT. Vibrio, 1985;p. 282 301. In E. H. Lennette A, Balows WJ, Hausler Jr and Shadomy HJ. Manual of clinical microbiology, 4th ed. ASM Press, Washington, DC.

22. Shanker P, Agarwal RK and sanyal SC. Experimental studies on enteropathogenecity of Vibrio cholerae serotypes other than 1. Zbl Bakt Hyg, I Abt Orig. A. 1982;252:514-524.

23. Mekalanos JJ, Mosley SL, Murphy JR and Falkow S. Isolation of enterotoxin structural gene deletion mulation in Virio cholerae induced by two mutagenic vibriophages. Proc Natl Acad Sci USA. 1982;79:151-155.

24. Nishibuchi M and Seidler RJ. Medium-dependent production of extracellular enterotoxins by non-O-1 Vibrio cholerae, Vibrio mimicus, and Vibrio fluvialis. Appl Environ Microbiol. 1983;45:228-231.

25. Igbinosa EO and Okoh AI. Vibrio fluvialis: an unusual enteric pathogen of increasing public health concern. Int J Environ Res Public Health. 2010;7: 3628-3643 